\title{
Priming against environmental challenges and proteomics in plants: update and agricultural perspectives
}

\author{
Georgia Tanou ${ }^{1,2}$ *, Vasileios Fotopoulos ${ }^{3}$ and Athanassios Molassiotis ${ }^{2}$ \\ 1 Department of Biochemistry and Biotechnology, University of Thessaly, Larissa, Greece \\ 2 School of Agriculture, Aristotle University of Thessaloniki, Thessaloniki, Greece \\ ${ }^{3}$ Department of Agricultural Sciences, Biotechnology and Food Science, Cyprus University of Technology, Limassol, Cyprus
}

\section{Edited by:}

Dominique Job, Centre National de la

Recherche Scientifique, France

\section{Reviewed by:}

Dominique Job, Centre National de la Recherche Scientifique, France

Françoise Corbineau, University Pierre et Marie Curie, France

\section{*Correspondence:}

Georgia Tanou, Department of Biochemistry and Biotechnology, University of Thessaly, Larissa 42221, Greece.

e-mail:gtanou@agro.auth.gr
Priming is the cellular state in which the harmful effects of abiotic stress factors in plants are hindered by pre-exposure to a stimulus, thus resulting in greater survival. It is becoming increasingly evident that priming techniques (e.g., external application of natural or synthetic compounds in plants) can enhance the tolerance of crops to environmental stresses. Innovative systems biology approaches such as proteomics are currently recognized as essential tools to understand the molecular mechanisms underlying plant responses to environmental stimuli and priming phenomena. The few published proteomic studies on priming in the context of environmental stress identify key protein targets and signaling pathways which are being involved in the alleviation of negative effects of stress factors. Since priming is a very promising strategy in modern crop production management, further research is needed in order to establish the global picture of priming phenomena against environmental challenges as well as to characterize specific priming-related protein indicators in plants.

Keywords: plants, priming, proteomics, acclimation, abiotic stress

\section{INTRODUCTION}

The process of priming involves prior exposure to an eliciting factor making plants more tolerant to future stress exposure (Figure 1). Since environmental stress negatively affects crop growth and productivity throughout the world (Krasensky and Jonak, 2012), studies on plant priming against abiotic stress factors are essential. Despite the agronomic and ecological importance of priming, however, little is known about the molecular mechanisms of priming in plants (Conrath, 2011). Meanwhile, proteomics is becoming a powerful tool to analyze the protein networks in plants upon imposition of environmental stimuli (Hossain et al., 2012). A number of recent studies also pointed out the role of protein post-translational modifications (PTMs), notably carbonylation and $S$-nitrosylation in plant defense and priming (Tanou et al., 2009, 2012; Astier et al., 2012), indicating that redox proteomics is critical in the study of priming responses. Thus, it is apparent that primed plants provide excellent scientific challenges for proteomic analyses which, among others, could significantly improve our understanding of how plant cells effectively respond to environmental cues. The aim of this mini-review is to provide an up-to-date overview demonstrating proteomic approaches used to characterize priming phenomena in plants toward environmental challenges.

\section{PRIMING PHENOMENA IN PLANTS}

Priming is an important mechanism of various induced resistance phenomena in plants against biotic stresses (Beckers and Conrath, 2007), whereas an analogy exists for vaccinated animals for an adaptive immunity to a disease and the ultimate prevention or amelioration of the pathogens infection effects. Proposed priming mechanisms include the accumulation of signaling proteins or transcription factors in an inactive form or the occurrence of epigenetic changes that are modulated upon exposure to stress and developed rapidly resulting in a more efficient defense mechanism (Bruce et al., 2007). Over the past few years, it has become apparent that priming phenomena are also involved in the context of environmental stress (Filippou et al., 2012). Several studies have examined priming events against environmental stimuli in various plant systems. For example, this was evidenced in the case of $\mathrm{NaCl}$ pre-treatment on Glycine max seedlings in order to induce acclimation to subsequent salt stress (Umezawa et al., 2000), acclimation of Deschampsia antarctica to cold stress (Chew et al., 2012) or application of low levels of Cd to Triticum aestivum for consequent Cd toxicity acclimation (Li and Zhou, 2012). Similar findings were shown for polyethylene glycol pre-treatment of Elaeagnus oxycarpa seedlings in order to induce acclimation to salinity (Murata et al., 2012), drought preconditioning of Lolium perenne for cold acclimation (Hoffman et al., 2012), and application of low levels of $\mathrm{Zn}$ for subsequent $\mathrm{Cd}$ toxicity acclimation in wheat (Li and Zhou, 2012). More interestingly, a primed state could also be induced in plants following an initial exposure to a priming agent, such as natural or synthetic compounds including nitric oxide (NO; Molassiotis et al., 2010), hydrogen peroxide $\left(\mathrm{H}_{2} \mathrm{O}_{2}\right.$; Molassiotis and Fotopoulos, 2011), hydrogen sulfide $\left(\mathrm{H}_{2} \mathrm{~S}\right.$; Li etal., 2012), $\beta$-aminobutyric acid (BABA; Tsai et al., 2011; Ton et al., 2005), and polyamines (Alcázar et al., 2010; Figure 1). This chemical-based priming against abiotic stresses somewhat resembles the systemic acquired resistance phenomenon in the case of biotic stresses (Stuiver et al., 1992; Uchida et al., 2002; Yang et al., 2007). Additionally, in analogy to the priming treatments on the vegetative parts of plants, seed water-based priming with controlled imbibition for seed invigoration and advance in 

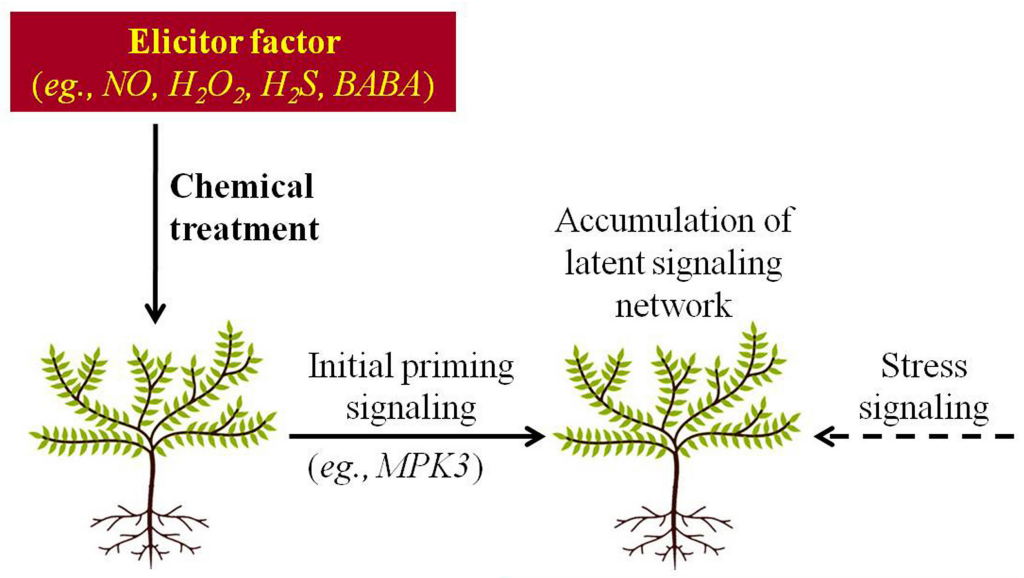

\section{Environmental challenge}

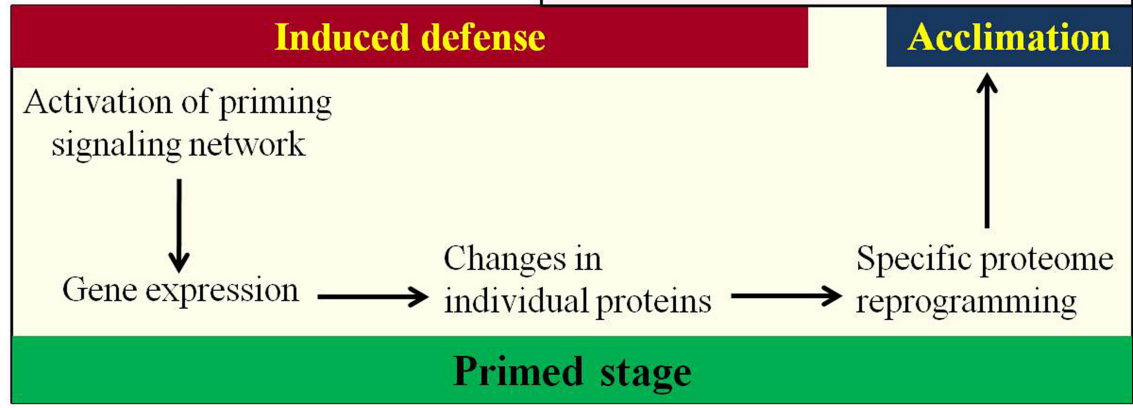

FIGURE 1 | Model describing the priming-based plant acclimation to environmental challenges. Chemical treatments of plants with priming elicitors resulted in the initial priming signaling leading the plants to a primed stage, in which a complex priming-related signaling network still remains inactive. Exposure to environmental stress stimulates the genetically programmed defense response in plants together with the activation of priming-related signaling network. This priming framework ensures spatiotemporally appropriate patterns of downstream stress-related gene and protein expression, ending in a specific proteome reprogramming that ultimately leads to stress acclimation. germination, in which long lasting effects occur after germination as well, has been widely characterized (Gallardo et al., 2001). This experimental evidence indicates that priming against environmental stress represents a fruitful area for future research in terms of both basic and applied agriculture science in order to promote the advent of, the more environmentally friendly, sustainable agriculture.

\section{PROTEOMICS AND PRIMING}

The agricultural relevance of priming in plants, as it is a costefficient strategy that increases the plant's ability to cope with stress, has motivated scientists to unravel the underlying cellular mechanisms (Beckers and Conrath, 2007). The last years studies using transcriptome and metabolome techniques have been conducted identifying transcriptional regulators and metabolite switchers and providing fundamental clues of how different networks are affected and interact during the priming process (Zimmerli etal., 2008; Luo et al., 2009). However, constraints in the estimation of gene expression levels, mRNA degradation or inefficiently translation, gene alternative splicing, as well as protein PTMs, processing and protein turnover, make the use of proteomics an essential tool covering the gap between the transcriptome and the metabolome (Renaut et al., 2006). In addition, proteomics studies give the opportunity to track subcellular proteomes and protein complexes (e.g., proteins in the plasma membranes, chloroplasts, mitochondria, and nuclei) and most importantly PTMs associated with priming (see later). Following two dimensional protein extract separation, together with the latest advances in mass spectrometry (MS)-based proteomics such as ion mobility separations, microchip-based proteome measurements, nanoscale reversed phase liquid chromatography, and capillary electrophoresis, as recently described by Angel et al. (2012), fundamental solutions exempting researchers from the elaborate protein separation procedure are now provided. Furthermore, significant developments in protein identification technologies (MALDI-TOF) and quantification strategies such as difference gel electrophoresis (DiGE), together with the availability of web accessible protein databases and the amount of information which are constantly being obtained through full sequencing of major agricultural plant species genomes (e.g., http://www. nature.com/nature/journal/v485/n7400/abs/nature11119.html\# supplementary-information), continuously improve the efficiency and reliability of proteomics rendering them a major field of functional genomics.

During the last years, various proteomic strategies characterize the protein changes in primed plants upon environmentally stressful conditions. Using citrus plants exposed to salinity, it was shown that $\mathrm{H}_{2} \mathrm{O}_{2}$ and sodium nitroprusside (SNP, a NO donor) were able 
to prevent the accumulation of a large number of $\mathrm{NaCl}$-responsive proteins via specific proteome reprogramming (Figure 1), which could prepare the citrus plant to respond more effectively to salt stress (Tanou et al., 2009). Furthermore, Bai et al. (2011), using a different NO donor ( $S$-nitroso- $N$-acetylpenicillamine, SNAP), showed that the accumulation of G-protein-associated proteins and the induction of antioxidant enzymes were the master mechanism through which salt alleviation was achieved in maize seedlings, in addition to activation of defense proteins, energy metabolism, and cell structure/division remodeling. Notably, the overlapping and/or unique routes of activated mechanisms among different priming agents was identified in BABA- or ABAtreated crabapple plants under drought conditions (MacArisin et al., 2009), as well as in $\mathrm{H}_{2} \mathrm{O}_{2}$ - or NO-treated plants upon salinity (Tanou et al., 2009). In specific, the similarities that were identified by MacArisin et al. (2009) in the proteome of ABAand BABA-treated crabapple seedlings using DiGE showed that BABA-induced abiotic stress tolerance is achieved by potentiating an ABA-regulated pathway. However, the significant differences in proteomic pattern between ABA- and BABA-treated crabapple seedlings indicate that BABA may also mediate drought tolerance via some ABA-independent pathways, including changes in cell-wall enzymes leading to suppression of lignin biosynthesis (MacArisin et al., 2009). Furthermore, Tanou et al. (2009) showed that $\mathrm{H}_{2} \mathrm{O}_{2}$ - and $\mathrm{NO}$-originated priming against salinity in citrus plants exhibit a number of similarities in terms of proteome expression signatures, as 45 leaf proteins were commonly targeted by $\mathrm{H}_{2} \mathrm{O}_{2}$ and $\mathrm{NO}$ during acclimation to salt stress. It is noted that the majority of $\mathrm{H}_{2} \mathrm{O}_{2}$ - and $\mathrm{NO}$-responsive proteins in this study corresponded to enzymes involved in Calvin cycle, such as 1,6bisphosphate aldolase, phosphoglycerate kinase, glyceraldehyde3-phosphate dehydrogenase, phosphoribulokinase, transketolase, and carbonic anhydrase, suggesting that reprogramming of specific pathways is required to achieve efficient priming-driven tolerance against salinity. In the same study, both $\mathrm{H}_{2} \mathrm{O}_{2}$ and $\mathrm{NO}$ pre-treatments alleviated salinity-induced protein carbonylation and shifted the accumulation levels of leaf $S$-nitrosylated proteins to those of unstressed control plants, suggesting that the oxidation and $S$-nitrosylation patterns of leaf proteins are specific molecular signatures of citrus plant vigor under stressful conditions (Tanou et al., 2009).

One of the best-characterized priming effects in biological systems concerns the application of pre-germination treatments in order to synchronize seed germination and invigorate the produced seedlings against adverse environments (Heydecker et al., 1973; Bradford, 1986; Chojnowski et al., 1997; Harris et al., 1999). The relevance of proteomics to characterize the mechanisms of seed imbibition and priming is best exemplified by studies showing that early steps of seed germination do not require de novo transcription while protein synthesis from the mRNAs stored in the mature seeds is absolutely required, hence revealing the role of proteins stored in the dry mature seed or translated from the stored mRNAs in the success of seed germination and seedling establishment (Gallardo et al., 2004; He et al., 2011). Early studies were also focused on the proteome characterization of model plants like Arabidopsis under the germinating developmental stages (Gallardo et al., 2001), followed by research on potential markers of seed vigor under primed and non-primed conditions in agricultural species such as alfalfa and sugar beet (Catusse et al., 2011; Yacoubi et al., 2011). Rajjou et al. (2006) proposed salicylic acid (SA), an elicitor of plant defense treatment as an invigorating application promoting Arabidopsis seed germination under saline conditions. SA re-induced the late maturation program during early stages of germination, affected the quality of protein translation, primed seed metabolism, provoked the synthesis of antioxidant enzymes, and mobilized seed storage proteins, as evidenced by a proteomewide analysis (Rajjou et al., 2006). Interestingly, the oxyproteome of Arabidopsis seeds was remarkably affected by SA (Rajjou et al., 2006), whereas protein oxidation and seed dormancy alleviation was also achieved in subsequent studies via seed pre-germination treatments with oxidizing compounds like methyl viologen (Oracz et al., 2007) or $\mathrm{H}_{2} \mathrm{O}_{2}$ (Barba-Espín et al., 2011). Similarly, protein carbonylation levels were strongly suppressed in salt-stressed citrus plants experiencing priming phenomena via treatments with $\mathrm{H}_{2} \mathrm{O}_{2}$ or NO before salt stress (Tanou et al., 2009). Using the same experimental system as well as a comprehensive proteomic analysis, the latter further showed that $S$-nitrosylation, the covalent attachment of an NO group to a reactive Cys thiol to form an $S$ nitrosothiol ( $\mathrm{SNO}$ ), as well as tyrosine nitration, the addition of a nitro group $\left(\mathrm{NO}_{2}\right)$ to one of the two equivalent ortho-carbons of the aromatic ring of tyrosine (Tyr) residues, are both involved in the acclimation of citrus plants to salinity conditions (Tanou et al., 2012). These observations indicate that redox proteomic approaches, like protein oxidation (carbonylation), nitrosylation, and nitration represent an important tool toward understanding priming phenomena in plants. Besides proteomic approaches, individual proteins have also been characterized as key components in the priming process. For example, a reverse genetics approach in Arabidopsis revealed that chemical priming is based on enhanced accumulation of mitogen-activated protein kinase 3 (MPK3) upon exposure to biotic or abiotic stresses (Beckers et al., 2009), suggesting MPK3 as a potential candidate for priming signaling (Figure 1).

\section{FUTURE PERSPECTIVES ON PRIMING PROTEOMICS}

It is noteworthy that several priming-induced chemical compounds, such as NO are increasingly recognized as mobile elements within plants (Molassiotis et al., 2010). Thus, because $\mathrm{NO}$ acts on proteins to alter their function and on the metabolic or signaling pathways in which these proteins are involved, it is important to characterize the systemic nature of priming phenomena in plants using proteomic approaches. In addition, many priming studies in plants use model chemical pre-treatment systems to induce priming against abiotic stress. This observation possibly indicates that primed plants possess molecular mechanisms that allow them to memorize previous priming events and generate memory imprints during the establishment of priming (Conrath, 2006, 2011; Bruce et al., 2007; Jaskiewicz et al., 2011; Slaughter et al., 2012; Tanou et al., 2012). Hence, a great deal of additional work is required to understand the systemic as well as the "memory" characteristics of priming and responsible protein-associated mechanisms in plants, especially in the era of redox-based PTMs. In addition, it has been hypothesized that priming involves accumulation of latent signaling 
components that are not used until challenge by exposure to stress (Beckers et al., 2009). It is therefore interesting to apply comparative proteomics analysis in plants treated with chemical priming agents and before the imposition of abiotic stress conditions. Since seed priming and plant priming involved different mechanisms it would be important to characterize distinct features as well as the potential interplay between them at proteome level. Finally, an intriguing challenge will be the application of the classic idea of priming in various biological processes with important agronomic features. For example, Minas et al. (2012) using a proteomic analysis showed that prolonged ozone application during cold storage in kiwifruits may act as antioxidant priming agent and anti-radical elicitor capable of rendering fruits

\section{REFERENCES}

Alcázar, R., Altabella, T., Marco, F. Bortolotti, C., Reymond, M., Koncz, C., Carrasco, P., and Tiburcio, A. F. (2010). Polyamines: molecules with regulatory functions in plant abiotic stress tolerance. Plant 231, 1237-1249.

Angel, T. E., Aryal, U. K., Hengel, S. M., Baker, E. S., Kelly, R. T., Robinson, E. W., and Smith, R. D. (2012). Mass spectrometry-based proteomics: existing capabilities and future direction. Chem. Soc. Rev. 41, 3912-3928.

Astier, J., Kulik, A., Koen, E., BessonBard, A., Bourque, S., Jeandroz, S., and Wendehenne, O. D. (2012). Protein S-nitrosylation: what's going on in plants? Free Radic. Biol. Med. 53 1101-1110.

Bai, X., Yang, L., Yang, Y., Ahmad, P., Yang, Y., and Hu, X. (2011). Deciphering the protective role of nitric oxide against salt stress at the physiological and proteomic levels in maize. J. Proteome Res. 10, 4349-4364.

Barba-Espín, G., Diaz-Vivancos, P., Job, D., Belghazi, M., Job, C., and Hernández, J. A. (2011). Understanding the role of $\mathrm{H}_{2} \mathrm{O}_{2}$ during pea seed germination: a combined proteomic and hormone profiling approach. Plant Cell Environ. 34, 1907-1919.

Beckers, G. J. M., and Conrath, U. (2007). Priming for stress resistance: from the lab to the field. Curr. Opin. Plant Biol. 10, 1-7.

Beckers, G. J. M., Jaskiewicz, M., Liu, Y., Underwood, W. R., He, S. Y., Zhang, S., and Conrath, U. (2009). Mitogen-activated protein kinases 3 and 6 are required for full priming of stress responses in Arabidopsis thaliana. Plant Cell 21, 944-953.

Bradford, K. J. (1986). Manipulation of seed water relations via osmotic priming to improve germination under stress conditions. HortScience 21, 1105-1112.
Bruce, T. J. A., Matthes, M. C., Napier, J. A., and Pickett, J. A. (2007). Stressful "memories" of plants: evidence and possible mechanisms. Plant Sci. 173, 603-608.

Catusse, J., Meinhard, J., Job, C., Strub, J., Fischer, U., Pestsova, E., Westhoff, P., Van Dorsselaer, A., and Job, D. (2011). Proteomics reveals potential biomarkers of seed vigor in sugarbeet. Proteomics 11, 1569-1580.

Chew, O., Lelean, S., John, U. P., and Spangenberg, G. C. (2012). Cold acclimation induces rapid and dynamic changes in freeze tolerance mechanisms in the cryophile Deschampsia antarctica E. Desv. Plant Cell Environ. 35, 829-837.

Chojnowski, M., Corbineau, F., and Come, D. (1997). Physiological and biochemical changes induced in sunflower seeds by osmopriming and subsequent drying, storage and aging. Seed Sci. Res. 7, 323-331.

Conrath, U. (2006). Systemic acquired resistance. Plant Signal. Behav. 1, 179-184.

Conrath, U. (2011). Molecular aspects of defence priming. Trends Plant Sci. 16, 524-531.

Corbineau, F. (2012). Markers of seed quality: from present to future. Seed Sci. Res. 22, S61-S68.

Filippou, P., Tanou, G., Molassiotis, A., and Fotopoulos, V. (2012). "Plant acclimation to environmental stress using priming agents," in Plant Acclimation to Environmental Stress, eds N. Tuteja and S. S. Gill (New York: Springer Science and Business Media) (in press). ISBN 978-1-46145000-9

Gallardo, K., Debeaujon, I., Vandekerckhove, J., Job, C., and Job, D. (2004). The effect of $\alpha$-amanitin on the Arabidopsis seed proteome highlights the distinct roles of stored and neosynthesized mRNAs during germination. Plant Physiol. 134, 1598-1613.

Gallardo, K., Job, C., Groot, S. P. C., Puype, M., Demol, H., Vandekerckhove, J., and Job, D. (2001).

more tolerant to subsequent senescence and ripening at room temperature. Clearly, the employment of proteomic approaches in priming agent-induced acclimation of plants to environmental challenges represents one of the most promising areas of fundamental and applied research for several years to come, whereas future proteomic studies on seed priming will also help to reveal novel markers of seed quality useful to ensure the best crop yields (Catusse et al., 2011; Corbineau, 2012).

\section{ACKNOWLEDGMENTS}

This work was supported by Greek "Education and Lifelong Learning" Operational Program funded by EU-European Social Fund and GSRT.

Proteomic analysis of Arabidopsis seed germination and priming. Plant Physiol. 126, 835-848.

Harris, D., Joshi, A., Khan, P. A., Gothkar, P., and Sodhi, P. S. (1999). On-farm seed priming in semiarid agriculture: development and evaluation in maize, rice and chickpea in India using participatory methods. Exp. Agric. 35, 15-29.

He, D., Han, C., Yao, J., Shen, S., and Yang, P. (2011). Constructing the metabolic and regulatory pathways in germinating rice seeds through proteomic approach. Proteomics 11, 2693-2713.

Heydecker, W., Higgins, J., and Gulliver, R. L. (1973). Accelerated germination by osmotic seed treatment. Nature 246, 42-44.

Hoffman, L., DaCosta, M., Ebdon, J. S., and Zhao, J. (2012). Effects of drought preconditioning on freezing tolerance of perennial ryegrass. Environ. Exp. Bot. 79, 11-20.

Hossain, Z., Nouri, M. Z., and Komatsu, S. (2012). Plant cell organelle proteomics in response to abiotic stress. J. Proteome Res. 11, 37-48.

Jaskiewicz, M., Conrath, U., and Peterhänsel, C. (2011). Chromatin modification acts as a memory for systemic acquired resistance in the plant stress response. EMBO Rep. 12, 50-55.

Krasensky, J., and Jonak, C. (2012). Drought, salt, and temperature stress-induced metabolic rearrangements and regulatory networks. J. Exp. Bot. 63, 1593-1608.

Li, D. D., and Zhou, D. M. (2012). Acclimation of wheat to low-level cadmium or zinc generates its resistance to cadmium toxicity. Ecotoxicol. Environ. Saf. 79, 264-271.

Li, L., Wang, Y., and Shen, W. (2012). Roles of hydrogen sulfide and nitric oxide in the alleviation of cadmiuminduced oxidative damage in alfalfa seedling roots. Biometals 25, 617631.

Luo, Z., Janz, D., Jiang, X., Göbel, C., Wildhagen, H., Tan,
Y., Rennenberg, H., Feussner, I., and Polle, A. (2009). Upgrading root physiology for stress tolerance by ectomycorrhizas: insights from metabolite and transcriptional profiling into reprogramming for stress anticipation. Plant Physiol. 151, 1902-1917.

MacArisin, D., Wisniewski, M. E., Bassett, C., and Thannhauser, T. W. (2009). Proteomic analysis of $\beta$-aminobutyric acid priming and abscisic acid - induction of drought resistance in crabapple (Malus pumila): effect on general metabolism, the phenylpropanoid pathway and cell wall enzymes. Plant Cell Environ. 32, 1612-1631.

Minas, I. S., Tanou, G., Belghazi, M., Job, D., Manganaris, G. A., Molassiotis, A., and Vasilakakis, M. (2012). Physiological and proteomic approaches to address the active role of ozone in kiwifruit post-harvest ripening. J. Exp. Bot. 63, 2449-2464.

Molassiotis, A., and Fotopoulos, V. (2011). Oxidative and nitrosative signaling in plants: two branches in the same tree? Plant Signal. Behav. 6, 210-214.

Molassiotis, A., Tanou, G., and Diamantidis, G. (2010). No says more than 'YES' to salt tolerance salt priming and systemic nitric oxide signaling in plants. Plant Signal. Behav. 5, 209-212.

Murata, N., Iwanaga, F., Maimaiti, A., Imada, S., Mori, N., Tanaka, K., and Yamanaka, N. (2012). Significant improvement of salt tolerance with 2-day acclimatization treatment in Elaeagnus oxycarpa seedlings. Environ. Exp. Bot. 77, 170-174.

Oracz, K., Bouteau, H. E., Farrant, J. M., Cooper, K., Belghazi, M., Job, C., Job, D., Corbineau, F., and Bailly, C. (2007). ROS production and protein oxidation as a novel mechanism for seed dormancy alleviation. Plant J. 50, 452-465.

Rajjou, L., Belghazi, M., Huguet, R., Robin, C., Moreau, A., Job, C., and 
Job, D. (2006). Proteomic investigation of the effect of salicylic acid on Arabidopsis seed germination and establishment of early defense mechanisms. Plant Physiol. 141, 910-923.

Renaut, J., Hausman, J. F., and Wisniewski, M. E. (2006). Proteomics and low-temperature studies: bridging the gap between gene expression and metabolism. Physiol. Plant. 126, 97-109.

Slaughter, A., Daniel, X., Flors, V., Luna, E., Hohn, B., and Mauch-Mani, B. (2012). Descendants of primed Arabidopsis plants exhibit resistance to biotic stress. Plant Physiol. 158, 835-843.

Stuiver, C. E. E., De Kok, L. J., and Kuiper, P. J. C. (1992). Freezing tolerance and biochemical changes in wheat shoots as affected by $\mathrm{H}_{2} \mathrm{~S}$ fumigation. Plant Physiol. Biochem. 30, 47-55.

Tanou, G., Filippou, P., Belghazi, M., Diamantidis, G., Fotopoulos, V., and Molassiotis, A. (2012). Oxidative and nitrosative-based signaling and associated post-translational modifications orchestrate the acclimation of citrus plants to salinity stress. Plant J. doi: 10.1111/j.1365313X.2012.05100.x [Epub ahead of print].

Tanou, G., Job, C., Rajjou, L., Arc, E., Belghazi, M., Diamantidis, G., Molassiotis, A., and Job, D. (2009). Proteomics reveals the overlapping roles of hydrogen peroxide and nitric oxide in the acclimation of citrus plants to salinity. Plant J. 60, 795-804.

Ton, J., Jakab, G., Toquin, V., Flors, V., Iavicoli, A., Maeder, M., Metraux, J. P., and Mauch-Mani, B. (2005). Dissecting the beta-aminobutyric acidinduced priming phenomenon in Arabidopsis. Plant Cell 17, 987-999.

Tsai, C., Singh, P., Chen, C., Thomas, J., Weber, J., Mauch-Mani, B., and Zimmerli, L. (2011). Priming for enhanced defence responses by specific inhibition of the Arabidopsis response to coronatine. Plant J. 65, 469-479.

Uchida, A., Jagendorf, A. T., Hibino, T., Takabe, T., and Takabe, T. (2002). Effects of hydrogen peroxide and nitric oxide on both salt and heat stress tolerance in rice. Plant Sci. 163, 515-523.

Umezawa, T., Shimizu, K., Kato, M., and Ueda, T. (2000). Enhancement of salt tolerance in soybean with $\mathrm{NaCl}$ pretreatment. Physiol. Plant. 110, 59-63.

Yacoubi, R., Job, C., Belghazi, M. Chaibi, W., and Job, D. (2011). Toward characterizing seed vigor in alfalfa through proteomic analysis of germination and priming. J. Proteome Res. 10, 3891-3903.

Yang, J., Zhang, J., Liu, K., Wang, Z., and Liu, L. (2007). Involvement of polyamines in the drought resistance of rice. J. Exp. Bot. 58, 1545-1555.

Zimmerli, L., Hou, B., Tsai, C. Jakab, G., Mauch-Mani, B., and Somerville, S. (2008). The xenobiotic $\beta$-aminobutyric acid enhances Arabidopsis thermotolerance. Plant J. 53, 144-156.

Conflict of Interest Statement: The authors declare that the research was conducted in the absence of any commercial or financial relationships that could be construed as a potential conflict of interest.

Received: 07 June 2012; accepted: 28 August 2012; published online: 11 September 2012.

Citation: Tanou G, Fotopoulos $V$ and Molassiotis A (2012) Priming against environmental challenges and proteomics in plants: update and agricultural perspectives. Front. Plant Sci. 3:216. doi: 10.3389/fpls.2012.00216

This article was submitted to Frontiers in Plant Proteomics, a specialty of Frontiers in Plant Science.

Copyright (C) 2012 Tanou, Fotopoulos and Molassiotis. This is an openaccess article distributed under the terms of the Creative Commons Attribution License, which permits use, distribution and reproduction in other forums, provided the original authors and source are credited and subject to any copyright notices concerning any third-party graphics etc. 